\title{
A Família no Japão: a noção de família ${ }^{1}$
}

\section{Noriko Mizuno \\ Professora na Universidade de Tohoku, Sendai, Japão.}

Somente no Século XX a família japonesa, pela primeira vez, foi objeto de regulamentação por um Direito Civil do tipo Ocidental. O primeiro Código Civil Japonês, denominado Código Civil de Meiji, foi promulgado na antevéspera desse século, em 1898.

Desde então, excetuando-se várias pequenas alterações, verificou-se, em matéria de Direito de Família, apenas uma reforma de grande envergadura, realizada em 1947, quase na metade do século. Se comparado ao direito civil francês, que tinha sido um de seus mais importantes modelos e que passou por várias reformas para se transformar profundamente, o direito de família japonês apresenta uma estabilidade impressionante.

Todavia, na prática, as transformações que a sociedade e a família japonesas sofreram durante esse século foram espetaculares.

De fato, a industrialização e a urbanização modificaram o ambiente e os modos de vida e de trabalho dos membros da família. Antes, numerosas eram as famílias que viviam da agricultura, enquanto que, atualmente, a maioria dos membros do lar são assalariados de empresas, o que reduziu o número de mulheres que, antigamente, cultivavam as terras com seus maridos, hoje, donas de casa ou assalariadas. Devido ao progresso da medicina, da saúde pública e à expansão do controle de natalidade, a antiga sociedade com numerosos nascimentos e mortes evoluiu para um número menor de óbitos e, finalmente, para um considerável decréscimo do número de nascimentos. A dimensão das famílias se reduziu e o problema se agrava, hoje, com as pessoas cada vez mais idosas, sofrendo de handicap mais ou menos sérios. Desapareceram as pequenas "Baby-sitters", que levavam as crianças do campo verdejante para as proximidades da cidade: as jovens mães restaram sós com

\footnotetext{
1 Artigo publicado in Revue Internationale de Droit Comparé, 4-2001, p. 831-851. Tradução autorizada pela autora, por Maitê Schmidtz (Bolsista PROPESQ/UFRGS) e revisão de Profa. Dra. Cláudia Lima Marques, UFRGS. Relatos japoneses apresentados durante a $6^{a}$ Jornada jurídica franco-japonesa, organizada pela Sociedade franco-japonesa de ciências juridicas e pela Sociedade de legislação comparada, em colaboração com a Associação Henri Capitant, em Tóquio e Sapporo, em setembro de 2001.
} 
suas pequenas crianças, num apartamento de concreto cercado do inferno da circulação rodoviária citadina. Antigamente, as crianças eram vítimas do tráfico infantil ou dos trabalhos rudes que lhes eram impostos, mas, atualmente, o são da violência de seus pais estressados. A uma taxa de casamento que estava entre as mais altas do mundo ${ }^{2}$, se sobrepôs bruscamente uma taxa inversa, recorde, de nascimentos, equivalente a 1,34 em 1999, o que acelera o envelhecimento da sociedade numa velocidade sem precedentes.

O antigo direito de família, em vigor de 1898 a 1947, apoiava-se num sistema familiar patriarcal, denominado "sistema de casas" e, após, qualificado como "feudal". Sob a atual Constituição de 1946, que prevê a dignidade do indivíduo e a igualdade de sexos na vida familiar (art. 24), o legislador de 1947 ab-rogou esse "sistema de casas" e estabeleceu o princípio da igualdade dos herdeiros: o Código Civil assim reformado tornouse bem mais avançado que os ocidentais em termos de igualdade.

Porém, nem o Código Civil de Meiji, nem a grande reforma de 1947 foram frutos de reivindicações espontâneas da sociedade japonesa. As codificações de Meiji tiveram como causa principal a pressão da diplomacia internacional, ou seja, as potências ocidentais requeriam o estabelecimento de uma legislação interna de estilo europeu como condição da supressão de seus privilégios de extraterritorialidade. Por tal motivo, os conservadores japoneses combateram com afinco a própria existência do Código Civil: eles sustentavam que a manutenção da paz familiar deveria ser confiada exclusivamente à moral e à educação, e não um sistema jurídico de direitos e obrigações; seria imoral, segundo eles, submeter à Justiça uma disputa entre membros de uma família. Por outro lado, a abolição do sistema de casas foi realizada, senão imposta, sob a ocupação americana que seguiu-se à Segunda Guerra Mundial: isso jamais teria sido feito sem tal acontecimento.

Ora, uma dupla questão se apresenta: a de saber se o surgimento do Código Civil de Meiji teve como efeito modificar bruscamente a ética familiar tradicional e, por outro lado, se a nova lei do após-guerra conseguiu, por seu caráter avançado, adiantar-se às transformações contemporâneas da família, podendo-se atribuir a isso a honra de ser uma lei estável.

A essas se soma uma terceira questão, concernente à tenaz oposição a um recente anteprojeto de reforma do direito de família. Esse foi preparado pelo Conselho de Legislação,

2 Uma oposição interessante das taxas por mil habitantes: o casamento passa de 9,3 em 1960, para 6,3 em 1998, enquanto que o divórcio aumenta de 0,74 , em 1960, para $1,94 \mathrm{em} 1998$. O casamento seguia uma curva deveras estável de 8 a 9 entre $1900(7,9)$ e durante os anos 1970 , salvo durante a Segunda Guerra Mundial (de 10 a 11) e os anos do baby boom $(10,5)$. Ao contrário, os divórcios, que tinham sido numerosos em $1900(1,46)$, tenderiam constantemente a diminuir até os anos 60, para voltar a subir depois. Quanto à taxa de nascimento por mulher, o primeiro número estatístico de 4,54 em 1947 não pára de diminuir. v. Ministry of Health and Welfare, Vital Statistics of Japan, 1998, vol. 1, pp. 80-81. 


\section{A Família no Japão}

juntamente com o Ministro da Justiça, e constitui uma das raras tentativas de reforma empreendidas, no Japão, a partir de um contexto unicamente interno. Além de consagrar a jurisprudência em matéria de divórcio, essa reforma tende, essencialmente, a criar a possibilidade do futuro cônjuge manter seu próprio nome de nascimento durante o casamento. No direito positivo, os futuros cônjuges devem optar, como nome conjugal, entre seus sobrenomes de nascimento (art. 750, C. Civil), sendo que, na prática, o sobrenome do marido é o escolhido na maioria dos casos. Visando, então, favorecer as mulheres casadas que desejam continuar a trabalhar mantendo seu próprio sobrenome, o anteprojeto de lei (1996) seria, na realidade, apenas uma reforma prioritariamente técnica ou somente um retoque entre outros - ao menos era essa a intenção dos redatores. E, todavia, uma viva oposição ao projeto mobilizou conservadores, o que teve como resultado o seu esquecimento no fundo de uma gaveta do ministério. Mas por que essa resistência?

A resposta a essas três questões se encontra, aparentemente, nas próprias características do Direito Civil japonês. Em algumas palavras, pode-se dizer que ele é bastante modesto, que ele se auto-limita; veja-se mesmo que ele é impotente na sua função de verdadeiro Direito de Família, enquanto, ao contrário, é válido como ideologia de família.

Modesto ou impotente, pois, se efetivamente o Código Civil tivesse regido e continuasse a reger a família japonesa, teria ele necessitado de muito mais modificações, correspondentes às mudanças da realidade familiar. Com exceção das disposições reescritas durante a grande reforma do após-guerra, o Código chegou a conservar quase totalmente o seu teor inicial, e eis porque alguns o denominam como um "grande código interminável". Mas a realidade é que esse era e continua sendo sempre um Código impotente e inapto para reger minuciosamente as realidades da família; e não foi a reforma do após-guerra que conseguiu prever as transformaçóes familiares posteriores.

De fato, como se verá mais detalhadamente, as disposições do Direito japonês sobre a família não são suficientemente ramificadas para determinar com precisão os direitos e obrigações dos membros da família, para manter a paz familiar e, sobretudo, para proteger os mais fracos nesta relação. Na codificação de Meiji, o legislador dedicouse, principalmente, a elaborar um "sistema de casas" sobre a base do regime preexistente dos "cadastros familiares" (koseki), registro do estado civil levantado casa por casa, e, para o remanescente, ele reproduziu o texto do Código Boissonade, do qual várias disposições tinham sido suprimidas durante as discussões no Senado da época. Isso fez do Direito de Família, para tratar de forma esquemática, um texto que determina os critérios de inscrição no "cadastro familiar", além de apresentar disposições referentes às sucessões. Esse caráter de impotência para reger a essência do direito de família não foi modificado pela reforma do após-guerra. 
Em compensação, o Código Civil de Meiji teve um efeito ideológico esmagador, na medida em que contribuiu para forjar uma consciência de família para a nação, decidindo o modo de ser legítimo da família no "sistema de casa". Provavelmente, o "sistema de casas" refletia, de certa forma, os sentimentos e as realidades da vida das partes, considerando-se que o cadastro familiar foi criado para ser um registro dos habitantes, mantido casa por casa. Porém, uma vez oficializado pela lei e propagado como que uma ideologia do Estado, o sistema contribuiu para canalizar a consciência nacional, o que não é desprezível. Para citar apenas um exemplo, os contemporâneos esqueceram completamente que antes do Código de Meiji, os cônjuges mantinham seu próprio sobrenome de nascimento, e o mesmo na inscrição de sua matrícula.

De um certo modo, o regime de cadastros teria, efetivamente, exercido, mais do que o próprio Código Meiji, um papel pedagógico mais concreto na consciência nacional. $\mathrm{Na}$ realidade, meio principal de justificação do estado civil e ligado ao registro de habitantes, os cadastros familiares são, além disso, submetidos ao princípio da publicidade permanente, ou seja, abertos, mesmo contra a vontade dos interessados, a todos aqueles que desejem consultá-lo. E seu conteúdo coloca quotidianamente em evidência que aqueles que estão no mesmo cadastro portam o mesmo sobrenome e formam uma família, uma casa.

Certamente, a reforma do após-guerra constituiu uma grande virada no atinente à liberalização e à isonomia, mas, na realidade, a consciência de "casa" sobreviveu, obstinadamente, ao sistema, no qual, aparentemente, era considerável o papel do nome patronímico. Na medida em que o nome representa um indivíduo e o seu direito à personalidade, obrigar um dos cônjuges a mudar de sobrenome na ocasião do casamento, devia - e deve sempre - marcar a consciência dos interessados com uma impressão determinante de mudança de "casa".

Era, assim, inevitável, de certo modo, que a introdução da proposta de facultar aos cônjuges a possibilidade de manter seu próprio nome durante o casamento se deparasse com uma resistência tenaz, pois isso teria como conseqüência desestruturar o papel do nome conjugal único, receptáculo da consciência de "casa". O confronto entre os "prós" e os "contras", ainda que ambos campos se confundissem freqüentemente, prosseguiu amplamente dentro da opinião e do princípio do mesmo nome conjugal e do regime de casamento ou de cadastros familiares. Essas controvérsias apresentam, por si só, de um lado, a sobrevivência de uma entidade-ideal de um "sistema de família" que forma o nome, o casamento e o cadastro familiar e, de outro lado, o fato de que, por tradição, o Direito Civil japonês, menos em seu papel de Direito de Família que em seu papel de ideologia familiar, tende a provocar, mais do que sóbrias discussões sobre suas instituições, uma rivalidade declarada. 
Ora, quando se tenta buscar a noção de família no Direito japonês, com a tela de fundo assim descrita, parece que, correlativamente à atitude geral de deixar uma grande margem aos fatos e aos jogos de costumes, o legislador se apóia, igualmente, sobre as maneiras reais da família, isto é, sobre a comunidade familiar de fato, quando os membros vivem e/ou trabalham juntos. Porém, na medida de seu factualismo, então, há espaço para se questionar se o Direito não apresenta insuficiências na proteção das pessoas fracas da família, particularmente as mulheres ${ }^{3}$. O exame dessa última questão completará a presente pesquisa, uma vez que o próprio sentido do vocábulo casamento, matrimonium, tende a definir a função da mãe; isso esclarecerá melhor a noção viva do Direito japonês sobre a família.

Em outras palavras, como a família é concebida no Direito japonês? E como ela é percebida pela mulher, causa senão final, no mínimo eficiente e até mesmo material da família?

\section{A PRIORIDADE PERSISTENTE DA NOÇÃO DE FAMÍLIA "COABITANTE E EXPLORADORA"}

Uma tentativa de análise da noção de família deveria, pelo menos, se interrogar sobre a delimitação desse agrupamento e seu papel econômico-social. Quem constitui a família? E que fazem os membros desse agrupamento?

A observação da realidade do direito japonês mostra que se continua a imaginar tal agrupamento como um corpo daqueles que vivem juntos e que exploram uma atividade de família.

Vejamos então, progressivamente, os aspectos da família "coabitante e exploradora".

\section{A. A Família "Coabitante"}

Diversas são as noções de família: num sentido mais amplo, compreende todos aqueles que são ligados por um laço de parentesco ou mesmo de meios no outro extremo, ao contrário, se encontra a família conjugal ou, sociologicamente, o núcleo familiar, consistindo no casal e seus filhos.

Isso constitui, em geral, o próprio modelo de família do direito francês, no qual a família legítima se opõe à família natural como a divisão fundamental da discussão. Já os

\footnotetext{
${ }^{3}$ Num contexto diferente, v. a crítica de M. Malaurie contra o "descompromisso" carbonieirista, MALAURIE e AYNES, Le droit civil, t. 3, La famille, $5^{a}$ ed., Paris, Cujas, 1995, n² 23, pp. 28-29.
} 
japoneses consideram a família, no fundo, como um "corpo daqueles que vivem juntos". E, nessa concepção, eles colocam em primeiro plano uma oposição entre a "família conjugal" e a "família de linhagem direta".

Isso significa dizer que esse agrupamento familiar é caracterizado, essencialmente, pela noção de coabitação, em que se tende a introduzir os eixos horizontal/vertical, para distinguir a família nuclear ou conjugal daquela que é ampliada pela coabitação de três gerações. E essa última concepção, que reflete, evidentemente, o antigo "sistema de casas", ainda não desapareceu da doutrina, ainda que a maioria dos autores atuais sustentem a primeira como definição de família.

Essa oposição doutrinária reflete a realidade estatística: em 2000, sobre uma totalidade de 45.545 .000 lares, 10,6\% comportavam três gerações, 59,1\%, famílias nucleares e $24,1 \%$ viviam sós; ou seja, entre as pessoas com mais de 65 anos, quase a metade $(49,1 \%)$ vivia com a família de um de seus filhos em 2000 , enquanto que em 1980 o número era maior do que dois terços $(69,0 \%)^{4}$. Embora o legislador de 1947 tenha suprimido o sistema de casas para privilegiar o modelo de família nuclear, a antiga concepção majoritária da grande família não desapareceu, nem da doutrina, nem dos costumes.

Diferentemente do Direito Civil francês, o legislador japonês de 1898 começou por erigir na definição jurídica essa concepção quotidiana do corpo de coabitantes. De fato, foi extremamente fácil delimitar juridicamente o círculo desses coabitantes, graças a uma instituição de estado civil, denominada "cadastro familiar".

E, como foi visto na introdução, é essa instituição de estado civil que tem por unidade a família-casa, que continua a servir de base decisiva na regulamentação da família no direito japonês, o que, curiosamente, obscurece um pouco o papel do Direito Civil de família. Há uma inversão na relação do principal e do subsidiário: no começo, era o registro, com o qual o legislador compôs o Direito Civil, sem nenhuma contradição.

a) O papel primordial do regime de "cadastros de famílias"

Para bem compreender as características do Direito de Família japonês, e mesmo da sociedade global, é indispensável conhecer o significado do regime de matrículas de casa.

${ }^{4}$ Segundo o cômputo geral da pesquisa sobre a vida da nação conduzida pelo Ministério da Saúde e do Trabalho. 
Após a Restauração de Meiji (1868), o novo governo criou, em 1871, essa instituição de "cadastro familiar" (koseki), registros que recenseavam inicialmente os habitantes de cada casa, para apanhar sua situação com fins de tributação e recrutamento.

Esse gênero de registros se encontra sob a mesma denominação nos países de cultura chinesa e no Japão antigo, mas o Meiji apresenta algumas originalidades. Inicialmente, a matrícula se estendeu até os empregados da casa, que foram logo registrados num cadastro distinto daquele dos pais e companheiros do chefe da casa. Um outro registro, o dos residentes temporários, foi instituído em 1914 para os casos em que os membros da família têm uma residência provisória: é a origem do atual registro obrigatório dos habitantes na prefeitura (desde 1951; Lei de 25 de julho de 1967). A reforma do após-guerra deixou intacto o regime de cadastros familiares, salvo no que tange a restringir a unidade à família conjugal, isto é, um casal e seus filhos não casados (Lei de 22 de dezembro de 1947).

Os cadastros familiares exerciam, então, uma função tripla: registrar, de uma só vez, a nacionalidade japonesa, os parentescos e uniões e o domicílio de uma pessoa. Os dois primeiros se extraem da própria lógica da instituição. E, por fim, o registro municipal dos habitantes compreende o local de matrícula do interessado. A ligação recíproca dos dois registros permite seguir todos os laços de parentesco e união de uma pessoa, apenas com seu nome e endereço.

Uma outra originalidade dos cadastros familiares é que estão submetidos ao princípio da publicidade, a tal ponto que não importa quando ou quem tenha acesso ao cadastro dos outros; apenas após a reforma de 1970 permitiu-se à prefeitura recusar a consulta ou o fornecimento de cópia quando é evidente que o pedido é feito com um objetivo ilegítimo (art. 10, Lei de 1947). Tratando desse modo o estado civil das pessoas, tal qual se tratam os imóveis ou os comerciantes, esse sistema de matrículas públicas é incontestavelmente incompatível com o direito ao respeito à vida privada.

Toda ocasião importante da vida social, aliás, justifica uma cópia do cadastro; e os japoneses, ao invés de contestar tal publicidade, continuam a temer que seu cadastro venha a ser "maculado" pelas menções "anormais", como divórcio, interdição, nascimento ilegítimo, etc., que constituem fonte de eventuais discriminações. Por tal motivo, eles irão até o ponto de evitar o nascimento ilegítimo...

O predomínio do regime de cadastros familiares sobre os princípios do direito civil se afirma, entre outras razões, por ser aquele base ou premissa desse. Além disso, por vezes o regime de cadastros suprime os princípios substanciais. 
Efetivamente, é graças à pré-existência desses registros que o legislador de Meiji chegou a regulamentar, enquanto membros de um corpo, de uma "casa", aqueles que estavam inscritos num mesmo cadastro, tanto o chefe da casa ( $k o s h u)$, quanto os membros de sua família. Eles portavam, por definição, o mesmo nome patronímico (uji), nome de casa (kamei), e eram considerados como membros de uma mesma casa.

É assim que, para fundar o "sistema de casas", concretizando-o no direito civil, o legislador apenas teve que substituir o regime de cadastros (antigos artigos 732 e ss. do Código Civil). A casa (ie) era dirigida pelo chefe da casa, que assegurava o sustento, a unidade moral e a direção dos membros de sua casa. Estando vinculado a uma obrigação alimentar em torno de si, o chefe da casa dispunha, em compensação, de uma série de prerrogativas importantes, incluindo o direito de dar seu consentimento a casamentos e adoções dos familiares, o direito de determinar o local de residência dos mesmos; e, em caso de desobediência, ele poderia expulsá-los de sua casa-cadastro. $O$ filho mais velho do chefe da casa o sucedia em sua função e herdava seus bens e a direção da casa; mesmo se fosse um filho ilegítimo, mas reconhecido e integrado na matrícula de seu pai, ele teria precedência sobre outro filho legítimo; porém, na falta de filho, legítimo ou natural, era a filha mais velha a sucessora de seu pai.

É necessário notar de pronto que, a partir de então, começou o divórcio entre o "agrupamento de coabitantes" que havia servido para a criação dos cadastros familiares e do "agrupamento dos membros de uma casa". Pois, mesmo se um dos coabitantes, sozinho, mudasse de residência para trabalhar em outro local, ele seria considerado sempre como membro da mesma "casa" de origem no registro, a menos que ele se separasse juridicamente para criar para si um novo cadastro. Apenas, apesar da separação entre a "coabitação" e a "co-matrícula", com a partilha do mesmo nome subsistirá a consciência de que os dois fatos devem, normalmente, coincidir.

Aí se encontra a origem da consciência de "casa". Mesmo após a guerra, ainda que o sistema de casas tivesse sido abolido e que o cadastro registrasse, doravante, apenas uma família conjugal, essa consciência sobreviveu, principalmente sobre a base do nome de casa, que se impõe a todos aqueles que aparecem num mesmo cadastro. $O$ nome conjugal deve ser, então, aquele do marido ou da esposa (art. 750 do C. Civil); a mulher casada que abandona o seu sobrenome deve pertencer à "casa" do marido. Parafraseando um grande poeta chinês do Século VIII, Du Fu (ou Tou Fou), que disse "o Estado destruído, restam as montanhas e os rios", diz-se "a casa destruída, resta o nome patronímico".

Além disso, pensou-se que as disposições do Código Civil tivessem cedido à prática da matrícula. 
Um exemplo impressionante se encontra no campo da filiação carnal. Como se extrai da lógica da instituição segundo a qual se deve registrar a filiação verdadeira, a jurisprudência chegou a criar um expediente para permitir a correção de menções falsas: esse expediente é denominado de "ação de declaração de inexistência da filiação". Sem ser prevista no Código Civil, essa ação é, segundo a jurisprudência, suscetível de ser formulada por qualquer um, não sendo prescritível. Embora esteja, substancialmente, em concurso com os litígios de filiação previstos pelo Código Civil, acabou por condenar os princípios e bases das ações clássicas tais quais a ação declaratória negativa de paternidade.

Outrossim, as disposições de origem francesa sobre o estabelecimento da maternidade natural pelo reconhecimento perderam seu interesse pela exigência da menção da mãe no cadastro, o que deu lugar a uma interpretação segundo a qual a filiação maternal se estabelece pelo próprio fato do nascimento.

Mas isso não é tudo quanto ao papel, ainda que um pouco obscuro, do Direito Civil de Família.

b) O papel um pouco obscuro do Direito Civil de Família

Como já foi visto, o direito civil japonês é, curiosamente, modesto ou impotente no domínio da família. Isso se manifesta, no mínimo, através de duas características.

Inicialmente, como bom aprendiz de Montesquieu ou de Portalis, o legislador se contentou em delinear as instituições com grandes traços e sem nuances.

Assim, não seria exagero dizer que o casamento japonês pareceria muito mais com o famoso PACS 5 francês em seus efeitos, salvo, evidentemente, no que tange à legitimidade dos filhos, ao pátrio poder e à sucessão de toda a propriedade por parte do cônjuge sobrevivente. Não há mais que sete artigos sobre os regimes de casamento, sendo dois sobre o regime primário e quatro sobre o contrato de casamento. $O$ regime jurídico é pura e simplesmente o princípio da separação (art. 762); e no que concerne ao pacto antenupcial, verificaram-se apenas $18 \mathrm{em} \mathrm{dez} \mathrm{anos,} \mathrm{entre} 1991$ e 2000. Essa lacuna quase total do direito dos regimes de casamento é suplantada pela parte relativa à sucessão da mietade do total da propriedade para o cônjuge sobrevivente, chamado à sucessão do falecido junto com seus filhos.

Aquilo que no direito japonês poderia ser comparado com o direito francês se encontraria, realmente, nos dois pontos seguintes: a função da publicidade do casamento que exerce a inscrição no cadastro familiar e a escassez de admissões do divórcio pela

${ }^{5}$ PACS - Pacte civil de solidarité - reconhecimento juridico de pessoas que vivem juntas, coabitantes. (NT) 
jurisprudência, em caso de desacordo entre os cônjuges, atinente à proteção às pessoas fracas.

Mas, correlativamente, o legislador possibilitou, em várias disposições, o livre acordo das partes. Isso, dessarte, constitui-se num de seus maiores traços seculares.

Com efeito, seja no casamento, no divórcio, na adoção ou na dissolução, as principais modificações do estado civil se fazem sem o controle jurídico ou judiciário, mas somente através da declaração à prefeitura, com a finalidade de inscrição no cadastro familiar. Entre outros, esse seria um dos maiores traços do Direito japonês: prever um divórcio por consentimento que deixa todos seus efeitos à livre disposição das partes. Além disso, não se encontra freqüentemente disposição que determine concretamente como decidir em caso de desacordo entre as partes, prevendo-se apenas que o litígio será confiado ao tribunal.

É que o direito estatal, sem se intrometer na intimidade da vida familiar, tende a respeitar ao máximo a autonomia das famílias e o jogo de costumes. Esse já foi o caso do legislador de Meiji no que tange aos chefe de "casa", mas o legislador do apósguerra não modificou esse caráter de liberalidade ou de disposições por assinatura em branco. Longe disso, ele o ampliou, poder-se-ia dizer, na medida em que a igualdade dos sexos ou dos filhos não permite mais dar o poder de decisão a apenas um entre os membros do casal.

Desse modo, mais do que um direito que tem como função distribuir adequadamente os direitos e obrigações entre os membros da família, o direito japonês de família se reduz em um direito que indica somente os critérios de inscrição nos cadastros familiares, além de determinar os efeitos concernentes às sucessóes. Poderse-ia dizer que se trata de um "direito administrativo da família".

Seria possível encontrar aí uma das explicações para o desenvolvimento do processo de conciliações, pois como fazer de outro modo num local em que as disposições legais são freqüentemente assinadas em branco, sem servir nem às partes nem ao juiz enquanto regras judiciais.

Nesse ponto, o legislador não parecia consciente do risco de eventuais abusos nas negociações das partes, nem da necessidade de prever, para os juízes, o que decidir em caso de não haver acerto, ou como eqüitativa ou concretamente decidir. Isso nos leva a propor o seguinte dilema: ou o legislador acredita profundamente em uma harmonia

"V. Jean CARBONNIER, "Le droit administratif du droit civil", in Pierre LEGENDRE (sob a orientação de), La bureaucratie et le droit, número especial da Revue historique du droit français et étranger, Paris, Sirey, 1975, p. 202 et s. 
pré-estabelecida nos moldes de Adam Smith, ou ele não se interessa pela família, tanto que não tocou nos maiores problemas de governo ou de administração?.

Assim sendo, se os membros da família vivem juntos, é para que trabalhem juntos. A família não é apenas um grupo de coabitantes, ela é também um corpo que exerce uma atividade, ao menos na noção tradicional.

\section{B. A Família "Exploradora"}

Uma outra imagem da "família exploradora" parece ter inspirado o legislador para elaborar o "sistema de casas" e continuaria, de certo modo, influenciando sempre as discussões dos civilistas.

a) A família exploradora, modelo do "sistema de casas"

A história da sociedade japonesa mostra que a família aparecia como uma comunidade econômica onde os membros se sustentavam reciprocamente durante suas vidas, defendendo-se e dando-se bens, e onde importava mais a solidariedade no trabalho coletivo que a solidariedade de sangue. Em contraste com a vida atual na sociedade industrializada, em que a maioria das famílias vive do salário para manter sua residência e para criar seus filhos, o Japão pré-industrializado consistia, freqüentemente, em famílias exercendo uma atividade doméstica, seja a agricultura, o comércio, o artesanato ou o antigo ofício de samurai, que necessitava da força de trabalho de seus membros.

Afirma-se com freqüência que o sistema de casas teve como modelo de origem as famílias de samurais, que eram autorizadas a portar oficialmente seu nome patronímico. Mas isso era quase o mesmo que ocorria com os agricultores, os comerciantes e os artesãos que, igualmente, viviam sobre uma herança transmitida de geração em geração, exercendo sua atividade de família em colaboração estreita entre seus membros e seus familiares próximos. A única diferença é que eles eram, a princípio, obrigados a se chamar oficialmente por um só nome, ao mesmo tempo que empregavam seu nome de casa para sua profissão.

Um samurai assegurava a continuidade de sua "casa" pela transmissão de seu benefício, que representa um direito ao salário acordado pelo shogoun ou por um daimyo. $\mathrm{Na}$ falta de um filho legítimo, a adoção se fazia como um meio de sucessão, com o acordo prévio do shogounat, ou às vezes mesmo após a morte do chefe de família. Mais energia era exigida dos burgueses ou dos camponeses para a exploração e para manterem sua atividade.

\footnotetext{
7 Os civilistas se dividem muito claramente entre "patrimonialistas" e "familialistas". Não é raro que um "patrimonialista" não tenha jamais ensinado o direito de família. Um eminente civilista declarou mesmo, um dia, que o direito de familia era mais relevante ao direito público.
} 
O chefe de família deveria dar provas de talento; não era raro preferir como herdeiro um genro, que o chefe de família adotava, quando do casamento de sua filha a um filho sem talento. É possível mesmo ver os exemplos de "constituição familiar" (kakun, preceitos fundamentais próprios a uma casa) da época, impedindo o acesso dos filhos à herança e prevendo o princípio da sucessão por um adotado.

Assim, importante era a sua propriedade, própria fonte de seu crédito e de sua personalidade.

As pessoas de bairros ou aldeias partilhavam, portanto, um sentimento natural muito intenso. Eles desejavam a prosperidade e a perpetuação de sua casa, o que incluía um profundo culto de seu ancestral fundador e de seus sucessores, os quais após suas mortes, poderiam se juntar tranqüilamente para proteger seus descendentes.

É com a imagem dessa entidade econômica que o codificador de Meiji elaborou o modelo de casa, dirigido pelo chefe da casa. Tendo que manter os membros da família, esse era dotado de grandes poderes, como o de determinar sua residência. Pela sucessão da direção da família, seu primogênito herdava tal situação.

A menos que pudessem se estabelecer em uma casa independente, os parentes colaterais masculinos, mesmo adultos, deviam permanecer submissos à direção de seu irmão mais velho, chefe da casa, e continuar a trabalhar em sua casa natal. Para as mulheres, o casamento significava, poder-se-ia dizer, trabalhar em "escravidão" para a sua sogra, verdadeira chefe da casa e freqüentemente severa em relação a suas noras.

Não se pode esquecer que, como mostra a própria influência da sogra com respeito a sua nora, a mulher casada, tornada chefe de casa, ocupava ao fundo um lugar co-explorador da mesma, em estreito consenso e colaboração com seu marido, muitas vezes apenas formalmente o chefe da casa.

Pode-se sempre encontrar as manifestações das principais preocupações das famílias que exploram suas atividades nas próprias disposições do direito civil moderno ou em suas aplicações sociologicamente características. Seguem-se dois exemplos.

Inicialmente sobre a função econômica do direito de sucessões: o trabalho fornecido a uma empresa de casa não era remunerado por um salário; a sucessão é, em compensação, considerada como um reembolso do preço desse trabalho. A ordem dos herdeiros legais é muito mais limitada que no direito francês, e inclui como colateral unicamente as irmãs e os irmãos, com a possibilidade de representação apenas até os sobrinhos e as sobrinhas (arts. 887 a 890). No atinente à partilha da sucessão, pode-se modificar as partes livremente pela negociação, podendo-se até concentrar a totalidade 
dos bens nas mãos de um só herdeiro. Essa última hipótese se verifica com freqüência quando esse segue a atividade da família; seus irmãos e irmãs, e muitas vezes o próprio cônjuge sobrevivente, fazem uma renúncia de direito ou de fato à sucessão ${ }^{8}$. Há também a eventualidade em que um dentre eles veja sua parte majorada por uma "parte de contribuição", quando se estima que ele contribuiu para a formação e a manutenção da herança (art. 904-2).

Por outro lado, a continuidade da casa e de sua atividade exige igualmente a continuidade do nome de casa. Isso explica porque a possibilidade de herdar um nome maternal é reconhecida constantemente desde do Código Civil de Meiji. Pois, se a filha com o seu marido sucede a seu pai, seu próprio nome patronímico é o mais comumente escolhido como nome conjugal, para que seus filhos herdem o nome maternal. Na falta de filhos de sangue, o nome de casa será continuado através da adoção.

Então, esse gênero de preocupações caracteriza a prática de adoções no Japão. Isso não é sempre feito para criar uma criança adotada, mas também, e principalmente, para se buscar mão-de-obra destinada a manter a "família" do adotante. No direito positivo atual, a adoção simples sem controle judiciário é possível a priori mesmo que o adotante seja, no mínimo, um dia mais velho que o adotado; além disso, é possível adotar um casal junto. Nas estatísticas, entre a totalidade dos casos de adoção em 1999, dois terços são de adoções concluídas com um maior; o outro terço compreende quase unicamente os casos de adoção de um neto do adotante ou de um filho de seu cônjuge; a adoção de um menor, que necessita apenas da autorização do tribunal de família, representa menos de 2000 casos.

Herdar o nome da família significa, uma vez mais aqui, herdar a atividade a seguir e os membros da família a sustentar, aqui compreendido, certamente, o chefe explorador aposentado; é quase sempre herdar uma "casa".

Mas a realidade das casas exploradoras não durou muito tempo. Isso porque, desde o começo do Século XX, a industrialização a desequilibrava, transformando as famílias de citadinos em simples lares de assalariados trabalhando em locais diversos; e após, uma onda de êxodo rural eclodiu a partir dos anos 60, aproximadamente, em razão do desenvolvimento acelerado da sociedade japonesa. Poder-se-ia dizer, de certo modo, que o sistema de casas devia desaparecer cedo ou tarde.

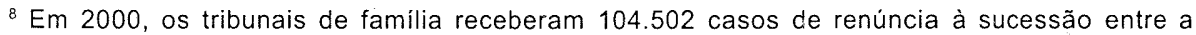
totalidade de 429.115 contendas em matérias não contenciosas (Annual Report of Judicial Statistics for 2000 , Family Cases, p. 8). Além disso, há uma prática de renúncia de fato, "atestado da parte sucessora igual a zero" por causa das liberalidades ou dos beneficios particulares recebidos em vida do de cujus. Segundo uma pesquisa conduzida em 1979 pelo Ministério da Agricultura, a sucessão atribuída integralmente a um só herdeiro, sucessor da exploração agrícola, representava até $85 \%$ dos casos em nivel nacional, e, na maioria dos casos, era por meio das renúncias de direito ou de fato.
} 
Isso não significa, todavia, que a consciência normativa no que tange à "casa" partilhe do destino da instituição. Na realidade, a instituição, seja da casa, seja de seu cadastro, havia extraído seu vigor dos sentimentos e costumes dos cidadãos, que viam ali uma consagração oficial no Código Civil de Meiji. E não se pode esquecer que foi ela, depois, que forjou, ao mesmo tempo, sua consciência normativa.

b) A subsistência da "consciência de casa"

O legislador aboliu o sistema de casas pela grande reforma de 1947, procedendo à alteração das disposições nos dois livros sobre a família e as sucessões.

A nova Constituição de 1946 havia declarado, em seu artigo 24, que "o casamento será concluído pelo simples acordo dos dois sexos e mantido pela sua cooperação mútua e sobre a base de direitos iguais dos cônjuges" e que, em se tratando de matérias sobre a família, "uma lei será votada sobre o fundamento da dignidade do indivíduo e da igualdade fundamental dos dois sexos".

O legislador guardou, todavia, o silêncio sobre a noção de "família". Ele não substituiu a família conjugal à "casa" abolida, nem tocou no regime de cadastros familiares em seu fundo técnico, salvo para restringir o objeto de uma matrícula ao âmbito de um casal e seus filhos não casados.

A maior parte dos autores considera a família conjugal como o tipo ideal próprio do direito civil atual, sendo dado o espírito "democrático" (segundo a máxima da época) das disposições da Constituição e o fato que a maioria das disposições legais tem por objeto determinar os direitos e obrigações de cada um dos cônjuges e de seus filhos menores.

Porém, nas discussões preparatórias à reforma, se pressupunha como objeto da regulamentação o âmbito daqueles que vivem juntos, justamente como havia feito o legislador de Meiji. O comitê encarregado de fixar as grandes linhas da reforma teve que evitar os termos de "abolição do sistema de casas", levando-se em consideração a forte oposição dos conservadores, para falar finalmente de "ab-rogar as disposições do Código Civil sobre o chefe de família e sua família e reger a vida coletiva dos familiares próximos, em conformidade com a realidade".

Ora, poder-se-ia ler algumas das novas disposições no sentido da "conformidade com a realidade", o que significa levar em consideração as modalidades efetivas da vida familiar da época, que evocavam um pouco da vida da "casa".

Assim, relativamente à obrigação alimentar, cujo alcance se ampliou em 1947, o artigo 877 do Código Civil dispõe que "os parentes em linha direta e os irmãos e 
irmãs devem-se, reciprocamente, os alimentos" e, também, que pode ser condenado, em casos particulares, a assegurar os alimentos a seus familiares próximos, parentes ou companheiros, até o terceiro grau. As modalidades são fixadas, na falta de consenso, pelo tribunal (art. 879). Outro sinal da concepção de uma família coabitante, o artigo 730 prevê que "os parentes em linha direta e os familiares próximos coabitantes devem se dar assistência".

Face a esse estado do texto, a corrente dominante na doutrina do após-guerra ou considera o artigo 730 como letra morta, ou restringe a obrigação alimentar ao limite da prestação econômica, excluindo a obrigação de cuidados concretos de pessoas idosas ou doentes. Porém, ainda que minoritários, certos autores não cessaram de sustentar as interpretações contrárias, para assegurar os cuidados com os pais idosos pelos membros da família.

Na realidade, o artigo 725, o primeiro artigo do livro IV sobre a família existente desde 1898, carrega uma enigmática definição de shinzoku, termo que significa o "parentesco" ou os "familiares próximos", mas praticamente sinônimo de "família" (kazoku). Foi previsto que "serão considerados como shinzoku os ascendentes até o sexto grau, os cônjuges e companheiros até o terceiro grau". Esse âmbito definido dos familiares próximos é, no fundo, extremamente vago para ter algum efeito concreto, apresentando, todavia, a particularidade de justapor o cônjuge, os pais e companheiros. Os autores falam muito pouco e não se sabe como qualificar essa definição. Para tentar uma hipótese, o legislador de Meiji teria desejado imitar as disposições francesas do gênero "até o décimo segundo grau", ou então ele teria se proposto a delimitar um âmbito daqueles que poderiam ser integrados na "casa", com os restantes ficando de fora. Poder-se-ia dizer um círculo de amizade e de visitação quotidianas, ou de consenso sobre as importantes decisões da "casa".

Enfim, a unidade do nome conjugal, prevista pelo artigo 750, se revela como uma das últimas sustentações da consciência de "casa". Os futuros cônjuges devem escolher um de seus nomes como nome conjugal; é o nome do marido que é escolhido em mais de $97 \%$ dos casos. $\bigcirc$ anteprojeto de lei proposto em 1996 pelo Conselho de legislação ao Ministro da Justiça continha a faculdade, para cada um que se casasse, de manter seu próprio nome, mas o Governo não pôde superar um vivo protesto dos parlamentares conservadores. Eles acreditavam que a dualidade facultativa de nomes conjugais faria com que a nora perdesse a consciência de que portava o nome de seu marido, de que estava entre os da família desse, e então obrigada a "fechar os olhos" de seus sogros e de cultuar os ascendentes da casa.

Até o presente ponto desse exame da noção de família no direito japonês foi visto que, por trás de uma legislação secular quase imóvel - salvo a abolição do sistema de casas -, o fundo do problema reside menos no campo jurídico que no nível da realidade vivida nos lares contemporâneos. 
Ora, no centro do lar se encontra a mulher.

\section{A SITUAÇÃO CONTEMPORÂNEA DA MULHER FACE À FAMÍLIA}

Devido a uma transformação inata da estrutura industrial na sociedade japonèsa, as famílias coabitantes e exploradoras foram substituídas por aquelas de assalariados indo trabalhar fora, o que, curiosamente, teve como efeito reforçar mais do que nunca a regra da divisão do trabalho entre os sexos, apesar da exigência que se faz ouvir cada vez mais de uma participação igual na sociedade.

Para retomar um clichê favorito do jornalismo francês, nos lares semi-abandonados pelos kamikazes das empresas de ponta japonesas, sua companheira resta só, condenada ao trabalho doméstico e aos cuidados dos mais fracos da família.

A situação dessas esposas, que contrasta com a das francesas quanto ao seu número, as convida a se questionar sobre o significado de "família" para elas mesmas.

Veja-se, de início, qual situação cobre a expressão: "os homens no trabalho, as mulheres no lar".

\section{A. "Os homens no trabalho, as mulheres no lar"}

Orientado essencialmente para os afazeres do lar, o trabalho feminino não é tratado, ainda, como ele mereceria no mercado de trabalho.

a) Os shadow works da mulher no lar

Durante o Século XX, o núcleo da coesão familiar passou do pai para a mãe, do chefe da casa para a mulher do lar $(\operatorname{shufu})$.

Um eminente historiador, M. Masanao Kano, constata os resultados nos seguintes termos: "Vocês conhecem o termo babby-sitter. (...) Nos lares contemporâneos, a mulher casada/mulher do lar/nora, encontra-se obrigada a preencher um triplo papel de "maridositter", de "filho-sitter" e de "idoso-sitter", e representa, nesse sentido, a "maternidade" ou uma "pseudo-maternidade" cada vez mais ampliada. Ou seja, se assiste hoje à generalização dos "lares sem pai" (ou "lares maternais"). Reduzido a essa forma, o lar aparece com dificuldade como uma unidade. É assim que a "maternidade" é preconizada pelo Estado como a "lixeira" de todas as contradições, ao mesmo tempo em que é valorizada pelos homens como a virtude de assumir, de boa-vontade, as "bagatelas da vida quotidiana". "Masanao KANO, Senzen - "le" no shiso (Antes da Guerra: a idéia de "casa"), Tokyo, Sôbunsha,
1983, p. 207 e s. 
Atualmente, a mão-de-obra no seio da família nascida da contradição de um laço familiar não é mais utilizada, principalmente num trabalho de produção como nas atividades de família de antigamente. Em tempos de trabalho assalariado, mesmo as atividades de família não são mais herdadas de pai para filho, mas exploradas freqüentemente sob a forma de sociedade comercial. O trabalho doméstico, ao contrário, necessita principalmente de uma mão-de-obra destinada ao lar e aos cuidados das crianças, dos enfermos e das pessoas idosas. Esse gênero de trabalho é denominado shadow work ${ }^{10}$, mão-de-obra fornecida a título gratuito e desprovida de valor de mercado, de modo que ela deve assumir fardos cada vez mais pesados, à medida que o capitalismo penetra na sociedade.

Enquanto as medidas de ajuda aos mais desprovidos financeiramente são atualmente equipadas até um certo grau pela ajuda social, as medidas destinadas às necessidades do shadow work são ainda muito pequenas na sociedade japonesa. Um sistema de seguridade social acaba de ser introduzido em 2000 em matéria de ajuda à velhice, mas isso não impede que reste, com respeito à ameaça de uma sociedade envelhecida, uma pressão social muito forte para que sejam responsáveis pelos idosos a família ou os parentes próximos, e, finalmente, a mãe de família.

Quando seus pais idosos chegam a sentir dificuldades para dirigir suas vidas sozinhos, sentem-se, então, de certo modo, fortemente chamados a ir, ou fazê-los vir, coabitar para lhes ajudar.

E é nesse momento que renasce esse âmbito de "casa", obrigando seus membros e, sobretudo a nora ou a mãe de família, a assumir o shadow work.

Mas, supondo que as mulheres fossem desoneradas, seria fácil para elas trabalhar fora?

b) A participação conjunta dos dois sexos na sociedade?

No Japão, encontra-se uma estrutura particular no mercado de trabalho, a chamada "prática de emprego à japonesa".

Efetivamente, as empresas empregam, por contrato de trabalho de duração indeterminada, um certo número de licenciados ou bacharéis no dia $1^{\mathrm{O}}$ de abril de cada ano. Pouco importando os diplomas ou as qualificações detalhadas, todos os novatos contribuem com um valor superior ao nível de seus salários, durante sua juventude, para perceber após sua maturidade um salário superior ao nível de sua produtividade, como prêmio por sua antigüidade.

${ }^{10}$ Ivan ILLICH, Shadow Work, Boston/Londres, M. Boyars, 1981. 
Essa prática japonesa supõe, implicitamente, a divisão do trabalho entre os sexos, em virtude da qual os homens se consagram ao trabalho na empresa e as mulheres ao lar e às crianças. Os homens exercem, a princípio, um emprego qualificado e as mulheres, um trabalho não qualificado, com uma grande diferença de tratamento entre as duas categorias. Por meio da segurança de emprego a longo prazo, os assalariados regulares perdem de forma considerável sua livre escolha das condições de trabalho, dificilmente podendo recusar trabalhar durante longas jornadas, ser transferido, quase sempre para longe e sem a sua família. É para evitar a demissão por motivo econômico, em tempos de crise, que as empresas os convocam para fazerem hora-extra, mesmo gratuitamente, como forma de limitar um sub-emprego durante os períodos de prosperidade.

Mesmo para as mulheres detentoras de um alto diploma, é de certo modo comum abandonar o trabalho muito jovem, quando do casamento ou da primeira gravide $z^{11}$, para apenas retomá-lo após os filhos terem crescido e, normalmente, em meio-turno.

É assim que os homens tendem a viver, infelizmente, mais próximos de sua empresa do que de sua família, que é, então, de alguma forma abandonada.

Ora, para assegurar a conformidade com o Tratado da ONU tendente a suprimir todas as formas de discriminação com relação às mulheres, o legislador procedeu, em 1985, a uma reforma total da lei de $1^{\circ}$ de julho de 1972 sobre a proteção das mulheres assalariadas, sob uma nova denominação de "lei tendente à igualar as chances de emprego entre os sexos".

Desde então, foi criada uma nova categoria de emprego qualificado para as mulheres, chamado sôgôshoku (categoria profissional geral). Ora, o emprego qualificado significa um trabalho semelhante àquele dos homens, dificilmente compatível com os deveres do lar; portanto, uma vez tendo abandonado esse trabalho ainda jovem, elas terão apenas uma pequena chance de serem reintegradas, salvo se a categoria permitir um emprego no curso da carreira. Mesmo nos casos raros de uma reintegração, elas sofrem uma perda considerável no montante global de seus rendimentos. Todos os regimes, de colocação, de seguro, de descontos, de pensão de aposentadoria, são concebidos levando em conta, implicitamente, a prática dos "homens no trabalho, mulheres no lar".

Daí subsistirem sempre diferenças consideráveis de condições entre os sexos. Mesmo em 1997, o salário feminino, em média, era equivalente a apenas $63,1 \%$ do salário masculino. Quanto às horas diárias de trabalho, os homens trabalham durante 5 horas e 36 minutos mediante salário e durante 31 minutos a título gratuito, enquanto as mulheres trabalham 2 horas e 48 minutos com salário e 3 horas e 50 minutos sem salário. O trabalho a título gratuito, representado essencialmente pelo shadow work no lar, é assegurado pelas mulheres, sendo 7,4 vezes mais longos que os dos homens.

${ }^{11}$ Há uma expressão "kotobuki taïshoku" (retrato de felicidade), ... felicidade em razão do casamento. 
A difícil compatibilidade do trabalho com os deveres do lar parece ser uma das causas da considerável queda da taxa de natalidade japonesa, com uma taxa de 1,34 filho por mulher em 1999. Essa queda deve-se em grande parte ao aumento, desde 1980, da taxa das mulheres entre 21 anos e a primeira metade dos 30 anos que permanecem solteiras.

Esse contexto levou o legislador a votar, em 1999, uma lei de orientação para uma sociedade com a participação conjunta dos homens e das mulheres. Essa lei visa a "neutralizar tanto quanto possível as influências que a prática (da divisão do trabalho entre os sexos) exerce sobre a escolha das atividades dos homens e das mulheres na sociedade" e obriga o Estado e a coletividade local a tomar as medidas necessárias para esse efeito. Mas, como se trata apenas de linhas diretrizes desprovidas de caráter concreto, é duvidoso que elas apresentem uma efetividade comparável à lei modificada de 1972.

Apesar desses tempos de depressão, em que até mesmo a segurança do emprego de salários regulares é ameaçada, não se encontrará sinais de mudança, exceto ver o tempo de trabalho ser ainda mais ampliado.

Porém, na própria parte a elas destinada, as mulheres se deparam com dificuldades suplementares.

B - "A mulher não encontra casa nos três mundos"?

Há um antigo provérbio, muitas vezes invocado ainda hoje: "A mulher não encontra casa nos três mundos". Ele é geralmente compreendido combinado com uma outra expressão antiga: "três obediências", significando que a mulher devia obedecer a seu pai durante sua juventude, a seu marido após seu casamento e a seu filho durante sua velhice. Conseqüentemente, o ditado era empregado no sentido de que a mulher não tinha refúgio nem em seu passado, nem em seu presente, nem em seu futuro ${ }^{12}$.

Isso também tem relação com o direito civil. Isso porque, como já se atreveu a dizer, sendo impotente o direito japonês de família, a antiga moral permanece parcialmente em vigor, na medida em que o direito não é suficientemente diferenciado para constituir um corpo de regras protetoras de pessoas fracas na família.

Pelo menos, é incontestável que as mulheres sofrem muito ao se divorciar. Além disso, há lugar para se questionar se elas não chegaram a sentir aversão pelo casamento, ou mesmo pela vida em casal.

\footnotetext{
12 Segundo a filosofia budista, todos os seres vivos estão condenados a errar em metapsicose dentro dos três mundos seguintes: o mundo dos desejos (kama-dhatu), o mundo das matérias (rupa-dhatu) e o mundo sem matérias (arupya-dhatu). Dizia-se que "não se tem casa nos três mundos" no sentido de que os homens não encontrariam ali asilo sem a independência do espirito. Dai esse provérbio que exprime a incerteza da condição feminina.
} 
a) As dificuldades para se obter o divórcio

Aparentemente, a taxa de divórcio seguiu uma curva ascendente desde os últimos anos. Mas o divórcio apresenta um certo número de dificuldades, principalmente para as mulheres do lar.

O divórcio é obtido, em mais de $90 \%$ dos casos no Japão, pelo consentimento, e é válido pela simples declaração na prefeitura. Obtido sem nenhum controle do judiciário, é um divórcio realizado pela auto-determinação das partes.

Somente não se pode supor de maneira alguma uma igual capacidade de negociação entre as partes; há sempre o risco de um abuso, de um repúdio disfarçado. Acreditava-se, de fato, que o marido depositava sua declaração na prefeitura sem o conhecimento de sua esposa, com carimbo e assinatura falsos. A famosa pressão da "casa" podia, assim, ser exercida; um provérbio era eloqüente, o qual dizia que "a mulher deixa (a casa), se ela não gerar um filho em três anos".

Mas após a guerra houve meios tidos como de repúdio disfarçado. Uma das maiores causas desse fenômeno consiste na jurisprudência formada a partir de $1952^{13}$, segundo a qual o divórcio não é, a princípio, admitido, quando é requerido por aquele cônjuge que causou a falência do casamento. Afirmando assim a chamada teoria de "divórcio-falência imposto (ao requerente)", essa jurisprudência teve como efeito espalhar no público a clara compreensão de que não se é obrigado a divorciar se não se quer, dando, substancialmente, a um dos cônjuges, um direito de veto ao divórcio.

Em compensação, tornou-se desde então extremamente difícil obter um divórcio na justiça. E isso teve uma repercussão negativa sobre a mulher que quer o divórcio, apesar do seu marido. Pois, seja por simples negociação entre as partes ou por processo de conciliação, se a mulher quer realmente o divórcio e, o mais rápido possível, ela se encontra, na realidade, obrigada a fazer todas as concessões sobre os efeitos do divórcio, para obter um acordo com o marido. Com medo de ficar difícil a solução desejada, ela aceita, às vezes, renunciar a todas as prestações econômicas, até mesmo à guarda dos filhos. Se a negociação se prolonga, não é raro que a mulher do lar não tenha mais nenhum meio financeiro, recusando o dinheiro do marido e sem ainda ter direito aos diversos subsídios de seguridade social. Da mesma forma, ela hesita igualmente antes da contenda na justiça, pois, além dos problemas do custo, do tempo e da dificuldade (a ajuda jurídica sendo irrisória), a apreciação judiciária é extremamente severa e detalhada sobre todos os fatos e gestos das partes durante o casamento (!). Tendo as portas de comunicação fechadas, algumas esposas se contentam em ficar separadas de fato no próprio seio de seu lar: existe hoje a expressão: "divórcio no seio do lar".

${ }^{13}$ Trib. Supr. 19 fev. 1952, Minshû, vol. 6, n² 2, p. 110. v. o relato de I. TAKIZAWA sobre o detalhe infra, p. 855 e s. 
Enfim, sobre o plano dos efeitos do divórcio, as prestações pecuniárias não dão, também, muita esperança. Em alguns casos, não há obrigação de alimentos após o divórcio. Em se tratando da prestação fixa, essa é determinada livremente em caso de negociação; na justiça, entre o marido que tem um salário anual considerável e sua mulher do lar sem rendimentos, o máximo será apenas a metade do valor das aquisições durante o casamento e que fazem parte dos bens comuns do casal. Além disso, uma possibilidade de se ver acordado um pretium doloris não èstá excluída, mas o montante não será considerável. Enfim, poder-se-ia, teoricamente, contar com a contribuição aos gastos do lar durante a separação anterior ao divórcio, mas na falta de meios de the executar judicialmente, isso é de fato ilusório.

Daí que o lar de uma mãe e de seus filhos após o divórcio recebe apenas um rendimento anual bem menor que a média geral dos lares.

Com o divórcio revelando-se difícil de se obter e sendo, de qualquer modo, desesperador, com a vida conjugal não sendo ela própria necessariamente agradável, é preferível o concubinato?

b) As dificuldades de examinar a vida em casal?

A situação na França parece impressionante, uma vez que se pode, francamente, ver ali uma justaposição institucional na balança do casamento e do concubinato ou união livre.

Esse fenômeno não existe de modo algum, ou ainda não, no Japão. De fato, a taxa de concubinato das mulheres solteiras está estimada em apenas 1,0 a 2,3\%, com a maioria dos casais optando pelo casamento. E o nascimento ilegítimo permanece no nível de $1 \%$. Aparentemente, uma fuga da família conjugal se desenha com a baixa gradual da taxa de casamento ${ }^{14}$. Mas, de todo o modo, a fórmula do concubinato não parece ter sido aceita no Japão.

Para dizer a verdade, era completamente diferente a situação sob o regime do direito de família de Meiji: reclamava-se da importância do casamento de fato, denominado naïen (laço íntimo). Isso porquanto o casamento "jurídico", previsto pelo Código de Meiji, era um recém-nascido ao lado daquele que era firmado por uma celebração regida pelo costume e feita na presença dos familiares e dos amigos. Eisso precisou de tempo para entrar nos costumes dos meios a serem moderados, bem como nos meios rurais, em razão da antiga prática do casamento de experiência. Enfim, uma das maiores causas do fenômeno de naïen era o mecanismo do sistema de casas, que tornava impossível o casamento entre um filho único e uma filha única, ambos destinados a suceder a direção de sua casa como próximo chefe de casa: a pobre Julieta, se ela se recusasse a aceitar um genro, deveria viver em concubinato com Romeu.

$\overline{14} \mathrm{~V}$. as estatisticas supra nota 1. 
Por seu lado, a doutrina e a jurisprudência construíram uma teoria chamada de "quase-casamento", para tratar os casais que vivem em concubinato como os cônjuges de direito comum, ao menos no plano dos efeitos do casamento, com exceção do nome conjugal e dos efeitos da sucessão. É o mesmo em matéria de seguro social. E essas interpretações são ainda válidas atualmente.

Um certo número de civilistas contemporâneos começa, todavia, a discutir sobre seu caráter adaptado à situação contemporânea. Pois a teoria do quase-casamento foi elaborada para encontrar um remédio para a situação dos concubinos - apesar deles terem se tornado raros atualmente -, e não para aqueles que, deliberadamente, optaram pela união livre, sem obstáculos maiores a seu casamento.

As reivindicações dos defensores da união livre apresentavam, então, um aspecto um tanto quanto semelhante àqueles dos homossexuais na França. Eram igualmente minoritários, e mais forte era a pressão social em favor do casamento, por sua vez bem "jurídico" e aprovado pelos interessados no seu meio. O que não estaria sem relação com um fenômeno de "cravatisation" geral da sociedade japonesa contemporânea, unidimensional e gestora.

Nesse contexto, o concubinato não se constitui numa escolha sensata, principalmente para as mulheres, que poderiam apenas se ver estigmatizadas como "desavergonhadas". Na realidade, a opinião é bem mais severa do que na França em relação à liberdade sexual da mulher. Foi somente em 16 de junho de 1999 que a pílula anticoncepcional foi permitida no Japão, várias dezenas de anos depois dos países ocidentais. Eles tinham medo de ver as mulheres obterem a liberdade de contracepção.

Apesar de ser necessário constatar que não foi a pílula que levou à queda da natalidade a 1,34 filhos, pode-se principalmente supor uma vaga aversão à vida de casal por parte das mulheres japonesas. Não é que houvesse claramente mais casais sem filhos ou com um filho único do que antigamente, mas há, certamente, mais jovens mulheres que retardam seu eventual casamento, para finalmente renunciá-lo.

O fato é que elas se recusam a formar um casal, conjugal ou maritalmente, diante da perspectiva do fantasma da "casa" assombrada pelo nome conjugal único, e a do shadow work do lar, a ser assumido inevitavelmente, mesmo no concubinato, em razão sobretudo da prática "masculino-centrista" do trabalho. Elas sabem, atualmente, se afirmar sozinhas, contando com seu alto diploma e se beneficiando na sua situação de "nobreza da condição de solteira". Elas não estão, talvez, completamente seguras de até onde elas poderão se manter nessa posição, mas elas não cederão mais facilmente à pressão das "idades convenientes", todas procurando um outro modo de viver em família... 


\section{CONCLUSÃO}

No domínio dos problemas da família, os constitucionalistas e civilistas japoneses deviam freqüentemente, e devem ainda às vezes, opor-se, em nome da liberdade, da igualdade entre os sexos e do direito à auto-determinação, a uma consciência de "casa" profundamente enraizada, invocando a tradição em cada ocasião. Mas as instituições que parecem, à primeira vista, contrárias a esses valores constitucionais, tais como o divórcio por puro consentimento, não sofreram discussões críticas. E as idéias de reforma centradas na Constituição visavam sobretudo aos problemas da diferença de idade da puberdade ou do tempo de viuvez, etc. Em geral, os debates se reduziam freqüentemente de um modo estéril em uma oposição de morais ou de visões de mundo.

Seria necessário lembrar, uma vez mais, que uma verdadeira esperança residiria numa legislação civil cuidadosamente elaborada, precisa e de aplicação efetiva e certa? Não existiria o direito para assegurar a liberdade e a igualdade de cada um, equilibrando os ônus e obrigações sem deixar que opressões ilegítimas ou injustificadas tenham livre atuação, para que todos nós possamos construir uma família sólida e estável, cheia de felicidade e conforme a nossa sensibilidade atual? 